\title{
A Novel Architecture for Ultra-Tight HSGPS-INS Integration
}

\author{
Guojiang Gao and Gérard Lachapelle \\ Positioning, Location and Navigation Group (PLAN) \\ Department of Geomatics Engineering, University of Calgary, Alberta, Canada
}

\begin{abstract}
Global Positioning System (GPS) currently fulfills the positioning requirements of many applications under Line-Of-Sight (LOS) environments. However, many Location-Based Services (LBS) and navigation applications such as vehicular navigation and personal location require positioning capabilities in environments where LOS is not readily available, e.g., urban areas, indoors and dense forests. Such environments either block the signals completely or attenuate them to a power level that is $10-30 \mathrm{~dB}$ lower than the nominal signal power. This renders it impractical for a standard GPS receiver to acquire and maintain signal tracking, which causes discontinuous positioning in such environments.
\end{abstract}

In order to address the issue of GPS tracking and positioning in degraded signal environments, a novel architecture for ultra-tight integration of a High Sensitivity GPS (HSGPS) receiver with an inertial navigation system (INS) is proposed herein. By enhancing receiver signal tracking loops through the use of optimal estimators and with external aiding, the capabilities of the receiver can be substantially improved. The proposed approach is distinct from the commonly used ultra-tightly coupled GPS/INS approaches and makes use of different tracking enhancement technologies used in typical HSGPS receivers, multichannel cooperated receivers and the current ultra-tightly coupled GPS/INS methods. Furthermore, the effects of inertial measurement unit (IMU) quality, receiver oscillator noise and coherent integration time on weak signal tracking are also analyzed.

Simulated test results in both static and dynamic testes show that, the designed INS-aided GPS receiver can track the incoming weak GPS signals down to $15 \mathrm{~dB}-\mathrm{Hz}$ without carrier phase locked, or $25 \mathrm{~dB}-\mathrm{Hz}$ with carrier phase locked. When there are multiple strong GPS signals in view, the other weak signals can be tracked down to $15 \mathrm{~dB}-\mathrm{Hz}$ with carrier phase locked.
KEY WORDS: ULTRA-TIGHT INTEGRATION, HSGPS, INS

\section{INTRODUCTION}

Standard Global Positioning System (GPS) technologies fulfill the positioning requirements of many applications intended for environments with clear Line-Of-Sight (LOS) to satellites. However, many Location Based Services (LBS) and applications such as vehicular navigation and personal location require positioning capabilities in environments where LOS to satellites is not readily available, e.g., urban areas, indoors and dense forest areas (e.g., Lachapelle et al., 2003). Such environments either completely block the GPS signals or attenuate them to a power level that is $10-30 \mathrm{~dB}$ lower than the nominal signal power (van Diggelen and Abraham, 2001). This makes it impractical for a standard receiver to acquire and maintain signal tracking, which causes discontinuous positioning in such environments.

In degraded signal environments, e.g., urban canyons and indoors, positioning availability and accuracy are affected by weak signal power, strong multipath/echoonly signals and receiver dynamics. The characteristics of degraded GPS signal environments are summarized in Table 1. In these environments, signal attenuation and strong specular reflectivity are primary sources of signal degradation. For vehicle navigation in urban areas, multipath/echo-only signals constitute interference sources that change quickly and behave randomly due to vehicle motion (MacGougan, 2003). The signal intensity for personal positioning in indoor environments (e.g., fireman positioning in buildings) is commonly 20-30 dB lower than that found outdoors (Lachapelle, 2007) To address this issue, High Sensitivity GPS (HSGPS) technologies (Watson et al., 2006), Assisted GPS (AGPS) systems (van Diggelen and Abraham, 2001), 
multi-channel co-operated receivers (Zhodzishsky et al., 1998) and cellular network-based solutions (Ma et al., 2007) have been developed. However, these technologies and systems still fail to maintain continuity of positioning with acceptable accuracies, specifically in the indoors. Thus, new receiver technologies have to be explored for enhanced signal acquisition and tracking performance.

Recently, ultra-tight integration of GPS and inertial navigation systems has received considerable attention for this purpose. In an INS-assisted GPS receiver, which is also called ultra-tightly coupled or deeply integrated GPS/INS, an external INS is used to provide receiver dynamics information to allow GPS receiver to do long coherent integration to track weak signals in sight (Soloviev et al., 2004). Measuring receiver dynamics through INS aiding enables the INS-assisted GPS receiver to track an incoming weak signal which is 20-30 $\mathrm{dB}$ lower or more than normal and therefore projects a strong light beam into the "indoor darkness" (Beser et al., 2002; Soloviev et al., 2004b; Kreye et al., 2000; Sennott, 1997).

Table 1 Characteristics in Different Operating Environments and Applications

\begin{tabular}{c|c|c}
\hline Features & $\begin{array}{c}\text { Urban Canyon } \\
\text { Vehicle } \\
\text { Navigation }\end{array}$ & $\begin{array}{c}\text { Indoor } \\
\text { Personal } \\
\text { Positioning }\end{array}$ \\
\hline Signal Fading & $10-30 \mathrm{~dB}$ & $20-30 \mathrm{~dB}$ \\
\hline $\begin{array}{c}\text { Multipath } \\
\text { Signal }\end{array}$ & $\begin{array}{c}\text { Strong, high } \\
\text { frequency }\end{array}$ & $\begin{array}{c}\text { Strong, low } \\
\text { frequency }\end{array}$ \\
\hline $\begin{array}{c}\text { Platform } \\
\text { Dynamics }\end{array}$ & Moderate & Low \\
\hline Map Matching & $\begin{array}{c}\text { Easy to } \\
\text { implement }\end{array}$ & $\begin{array}{c}\text { Maps not readily } \\
\text { available }\end{array}$ \\
\hline $\begin{array}{c}\text { Desired } \\
\text { Receiver Size }\end{array}$ & Moderate & Small \\
\hline
\end{tabular}

Table 2 (Gao, 2007) summarizes the performance of HSGPS, multi-channel co-operated receivers (also called COOP tracking receivers) and INS-assisted GPS receivers. It shows that an INS-assisted GPS receiver is far superior to the other positioning technologies mentioned above and offers the greatest potential for meeting navigation and positioning requirements under attenuated signals. In INS-assisted GPS receivers, velocity aiding from INS enhances the GPS phase lock loops (PLL), which are the weakest loops in the receiver. Furthermore, full navigation capability, including carrier phase output under attenuated signals, is preserved in INS-assisted GPS receivers. This availability of accurate carrier phase measurements is deemed necessary for many high-accuracy applications.
The paper continues with the discussion on the current ultra-tightly coupled GPS/INS systems and other weak signal tracking technologies, such as HSGPS and multichannel co-operated receivers. Then, the design of a novel INS-assisted GPS receiver for degraded GPS signal tracking is introduced. The proposed architecture is distinct from current ultra-tightly coupled GPS/INS systems and uses a combination of different tracking technologies like HSGPS or multi-channel co-operated GPS receivers or traditional ultra-tightly coupled GPS/INS approaches. Some system design issues, such as IMU quality requirements, the limits of very long coherent integration time and receiver clock error compensation, are also addressed. Information about the testing tools utilized herein, including an INS simulator developed for this purpose, is provided. Test results and analysis are then presented using simulated data sets to assess the performance of the INS-assisted GPS receiver, followed by conclusions.

\section{CURRENT ULTRA-TIGHTLY COUPLED GPS/INS SYSTEMS}

Based on the type of Kalman filter used, ultra-tight integration can be implemented in three different ways (Gao, 2007), namely: (1) loosely coupled Kalman filterbased ultra-tight integration, (2) tightly coupled Kalman filter-based ultra-tight integration, and (3) ultra-tightly coupled Kalman filter-based ultra-tight integration. Figure 1 summarizes the different architectures. Figure 2 shows two different types of architectures for INSassisted GPS receivers, as proposed by Gautier and Parkinson (2003), Alban et al. (2003) and Gustafson et al. (2000).

The first architecture shown in Figure 2(a) is based on a loosely or tightly coupled integration scheme. All individual DLL (delay lock loops) and PLL are inside the receiver. The Kalman filter utilizes either raw measurements or processed positions and velocities from the GPS receiver to update the INS periodically. The updated INS information is then used to predict the phase and Doppler used as aiding to the receiver. Thus, based on the type of measurements used for updating the INS, these strategies can be classified as loosely coupled Kalman filter-based ultra-tight integration or tightly coupled Kalman filter-based ultra-tight integration. However, in the second architecture shown in Figure 2(b), an ultra-tightly coupled Kalman filter is used in place of conventional in-receiver PLLs and, in some cases, even DLLs. This filter operates on in-phase (I) and quadra-phase $(\mathrm{Q})$ components of the signal directly. This 
integration strategy is referred to as ultra-tightly coupled Kalman filter-based ultra-tight integration.

Most of the work done in ultra-tight integration of GPS and INS has focused on the above three integration strategies. Although these new architectures offer flexibility, from the point of view of information theory, it is suggested herein that simply adopting different kinds of Kalman filters will not improve positioning performance of GPS/INS integrated systems significantly. This concept is best illustrated by an analogy of water in a river. Although water looks very different at higher, medium, and lowest points of the river, the volume of water is the same at all these points. This is the case for line-of-sight environments, where a tightly coupled Kalman filter will not provide significant improvements in an integrated system performance as compared to a loosely coupled filter.

There are also some specific limitations in present architectures. The first limitation is that the receiver tracking capability is sensitive to IMU quality. For reliable aiding from INS, a velocity accuracy of $1 \mathrm{~cm} / \mathrm{s}$ along the LOS direction is required from the INS solution (Soloviev et al., 2004a), which requires a high quality IMU.

Table 2 Performances of Different Positioning Methods under Attenuated Signals

\begin{tabular}{|c|c|c|c|c|}
\hline Items & HSGPS & $\begin{array}{l}\text { CO-OP } \\
\text { Tracking }\end{array}$ & $\begin{array}{l}\text { GPS/INS } \\
\text { Ultra-tight } \\
\text { integration }\end{array}$ & Notes \\
\hline $\begin{array}{l}\text { Tracking } \\
\text { Sensitivity }\end{array}$ & Good & Good & Excellent & $\begin{array}{l}15-25 \mathrm{~dB} \text { lower than regular signals for HSGPS and CO- } \\
\text { OP tracking; } 20-30 \mathrm{~dB} \text { for ultra-tight integration }\end{array}$ \\
\hline $\begin{array}{l}\text { Acquisition } \\
\text { Sensitivity }\end{array}$ & Poor & Good & Excellent & $\begin{array}{l}\text { Because of long integration time, long Time-To-First Fix } \\
\text { (TTFF) for HSGPS; INS measurements and/or information } \\
\text { from other tracking channels can be used to speed up the } \\
\text { acquisition process in ultra-tight integration and CO-OP } \\
\text { tracking, especially in hot start. }\end{array}$ \\
\hline $\begin{array}{c}\text { Re-Acquisition } \\
\text { Capability }\end{array}$ & Poor & Good & Excellent & $\begin{array}{l}\text { Due to long pre-detection integration time (PIT), re- } \\
\text { acquisition is time-consuming in HSGPS; Aiding from INS } \\
\text { measurements facilitates rapid re-acquisition in ultra-tight } \\
\text { integration. }\end{array}$ \\
\hline $\begin{array}{l}\text { Position Data } \\
\text { Up Rate }\end{array}$ & Low & Low & High & $\begin{array}{l}\text { In ultra-tight integration, the data rate can be increased to } \\
\text { above } 100 \mathrm{~Hz} \text { using INS aiding, with a Kalman filter } \\
\text { running at a low recursive rate. }\end{array}$ \\
\hline $\begin{array}{c}\text { Positioning } \\
\text { Accuracy }\end{array}$ & Poor & Good & Excellent & $\begin{array}{l}\text { In HSGPS, positioning accuracy is degraded by multipath } \\
\text { signal and frequency/phase tracking error; In ultra-tight } \\
\text { integration, INS solution can help in blunder detection and } \\
\text { noise compression (by using long time integration). }\end{array}$ \\
\hline $\begin{array}{c}\text { Carrier Phase } \\
\text { Output }\end{array}$ & Poor & Good & Excellent & $\begin{array}{l}\text { In HSGPS, limited benefit for PLL tracking, and thus } \\
\text { difficult to output carrier phase observation; Ultra-tight } \\
\text { integration method can output precise phase observation } \\
\text { and avoid/reduce cycle slips. }\end{array}$ \\
\hline $\begin{array}{l}\text { Dynamic } \\
\text { Response }\end{array}$ & Poor & Poor & Excellent & $\begin{array}{l}\text { HSGPS is used mainly for low dynamic users. Ultra-tight } \\
\text { integration can be used for both low and high dynamic } \\
\text { users and thus in both commercial and military applications }\end{array}$ \\
\hline Receiver Size & Small & Small & Moderate/Big & $\begin{array}{l}\text { For HSGPS, no need for any other hardware; a good size } \\
\text { under Ultra-tight integration for MEMS IMU }\end{array}$ \\
\hline Power Cost & Low & Low & Moderate/High & $\begin{array}{l}\text { For HSGPS, no other hardware required so no additional } \\
\text { power cost. For Ultra-tight integration, additional external } \\
\text { sensor needed, so more power is required. }\end{array}$ \\
\hline $\begin{array}{l}\text { Multipath } \\
\text { Mitigation }\end{array}$ & Poor & Good & Excellent & $\begin{array}{l}\text { Ultra-tight integrated navigator can detect multipath signals } \\
\text { and track weak LOS signals directly in urban areas and } \\
\text { indoor environments. }\end{array}$ \\
\hline
\end{tabular}




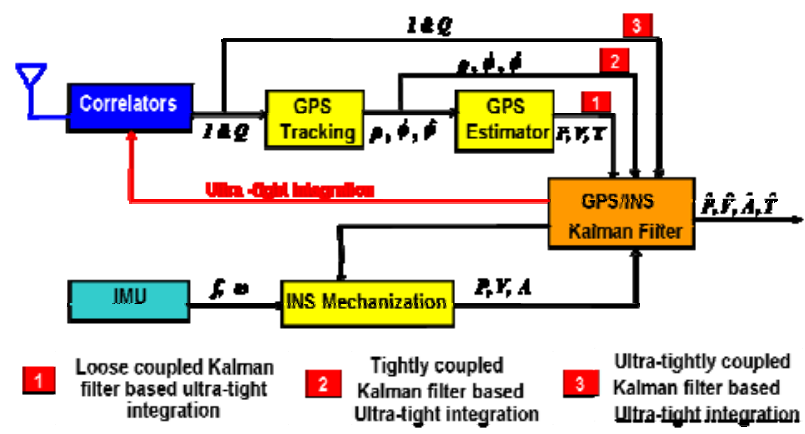

Fig, 1 Ultra-tightly Coupled GPS/INS with Loosely, Tightly or Ultra-tightly Coupled Kalman Filter

The second limitation is that before the integrated system moves to attenuated signal environments, it has to be initialized under LOS environments, which includes GPS-only receiver initial acquisition and INS initial alignment.

Furthermore, the accuracy estimation of a Kalman filter relies on the assumption of correct stochastic modeling of both system measurement errors, which may not be possible in severe urban canyon environments. For vehicle navigation in urban canyons, GPS measurement faults such as those caused by multipath or echo-only signals are very significant. Also, IMU measurement errors may not be compensated effectively, which ultimately degrades the receiver tracking performance.

Small INS velocity errors usually remain after the INS is well aligned with GPS measurements and the vehicle's motion contains sufficient dynamics to make all the INS error states observable. However, in the static case or where the vehicle motion does not contain enough dynamics to ensure observability, the accuracy of the Doppler information from the INS may be of poor quality. A particular concern is the poorly observable states of the azimuth and gyro bias. If the estimates of these states are of poor quality, the velocity component errors provided by a low cost INS in static situations can be very large. It should also be noted that the dynamics that needs to be estimated and compensated by the INS are not limited to the LOS velocity component but to all other components. For example, an erroneous azimuth estimate can result in dynamics errors due to "phase wind-up" effects (Tetewsky and Mullen, 1996; Don et al., 2005).

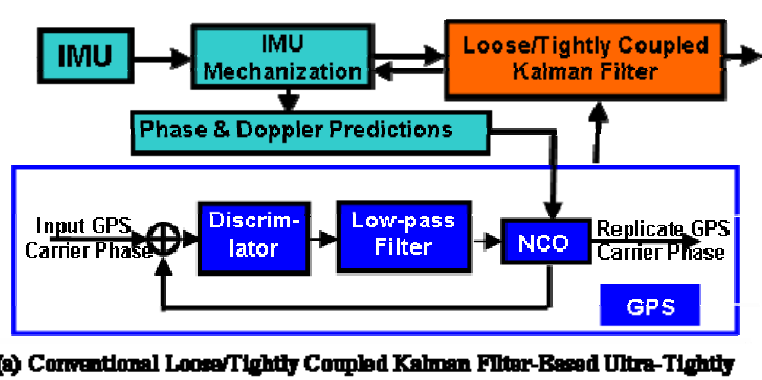

(a) Courintional Loose/Tighth Coupled Kahngen Filter-Besed Ultre-Tightly Couplad CPRINS Intedration Prosentod by Stanford Uniwarsity

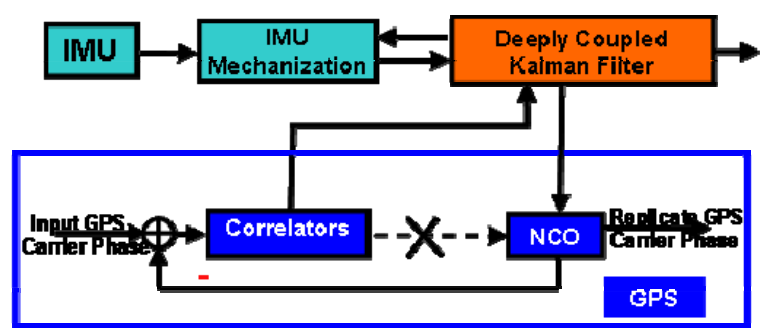

(b) Ultra-tiohtly Coupled Kalman Flter-Based Ultre-Tightly Coupled GPSINS tenteration Proposed by Draper Lab

Fig. 2 Two Different Architectures of Current Ultratightly Coupled GPS/INS

Furthermore, when a low cost MEMS-based INS is involved in an INS-assisted GPS receiver, because of the very low accuracy and very poor stability of IMU sensors, the INS velocity errors might contain jumps or blunders. These large errors may cause major problems in an INS-assisted GPS receiver. Given the GPS/INS Kalman filter observability issue discussed above, MEMS-based INS/GPS ultra-tight integration is still a major challenge.

\section{DESIGN OF NOVEL INS-ASSISTED GPS RECEIVER}

To overcome the limitations of current INS-assisted GPS receivers, a technique based on multi-channel cooperated tracking (COOP tracking) is proposed herein to estimate and track the Doppler prediction errors caused by INS errors. This technique is fully described in Gao (2007). Initial results were presented by Gao and Lachapelle (2006).

The architecture of the proposed integration system is shown in Figure 3. The ultra-tightly integrated system used the software receiver GNSS_SoftRx ${ }^{\text {TM }}$ (Ma et al., 2004) as a starting point. The proposed strategy includes three loops. The first loop includes the conventional loosely or tightly coupled Kalman filter, which predicts 
the user Doppler based on information from the INS. In this study, a loosely coupled Kalman filter is suggested. This loop provides external Doppler aiding and clock error correction from the INS. In order to decrease the effects of INS positioning errors on receiver Doppler prediction and receiver clock error compensation, a COOP loop is used as the second loop to estimate the carrier Doppler error and receiver clock error caused by INS positioning errors. Thus, the INS and COOP loops operate together in order to provide a nearly perfect reference for receiver dynamics and receiver clock errors. Since receiver dynamics is removed from the signal, long coherent/non-coherent integration time for individual PLLs and DLLs becomes possible, which constitutes the third loop of the proposed architecture. Thus, the PLL/DLL loops track the differences between the incoming and the local signals, which have been compensated by INS and COOP loops.

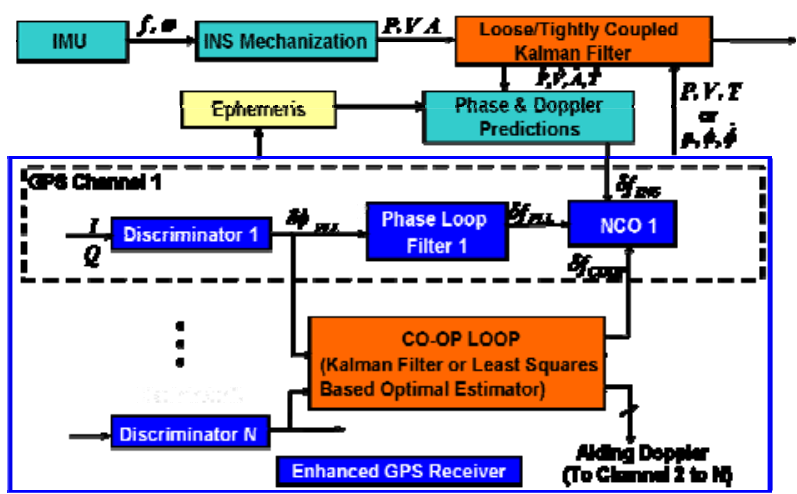

Fig. 3 Proposed Architecture of Ultra-tightly Coupled GPS/INS

The characteristics and advantages of the proposed system can be summarized as follows:

1 The HSGPS receiver optimizes parameterization and employs data wipe off technology for long coherent integration. This structure enables initialization in a weak signal environment.

2 To provide INS aiding to the GPS receiver, a loosely/tightly coupled GPS/INS approach such as that used by Petovello (2003) in the SAINTTM software is suggested to handle INS measurements and provide a corrected INS solution for receiver aiding.

3 The multi-channel cooperated tracking loops track the weak signals and eliminate the effects of INS errors. The design of this estimator is discussed later in this section.

4 The individual DLL/PLLs are different from those of traditional ultra-tightly coupled GPS/INS systems, which adopt ultra-tightly coupled Kalman filters for signal tracking. In this design, traditional sophisticated DLL/PLLs are still located in every individual signal tracking channels, as shown in Figure 3. Furthermore, the individual DLL/PLLs are enhanced using a data wipe off technology mentioned in item 1 to perform very-long coherent integration. The individual DLL/PLLs are combined with INS aiding loops and COOP loops to track both strong and weak signals.

5 Since INS is used in this approach to mainly provide receiver dynamics information, any other sensors such as odometers or radars can replace INS sensors to provide Doppler measurements for the enhanced receiver. This provides an effective capability to reconfigure the software receiver to suit various aiding hardware.

\section{A. Multi-Channel CO-OP Tracking Loop}

Figure 4 shows the modular design of the multi-channel co-operated tracking loops, i.e., the COOP tracking loops. The basic strategy of COOP tracking is to project signals from the channel domain to the position domain and then try to track/estimate the signals in the position domain. Then the signals are projected back to the channel domain for Doppler removal (Zhodzishsky et al., 1998).

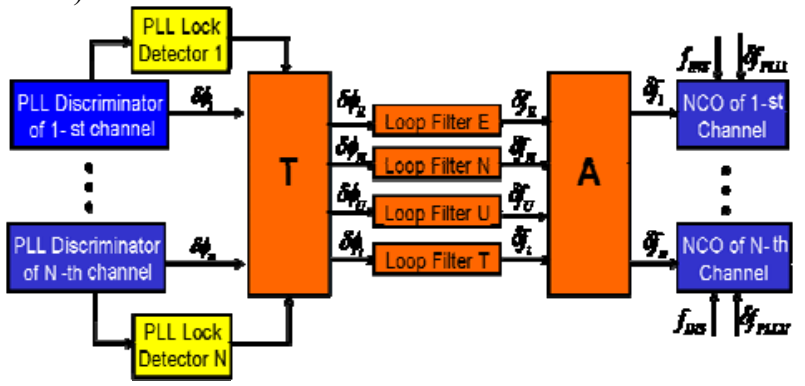

Fig. 4 Architecture of co-operated (CO-OP) Tracking Module

In Figure 4,

$$
\begin{aligned}
& T=T^{n}=C_{e}^{n} T^{e} \\
& A=A^{n}=A^{e} C_{n}^{e}
\end{aligned}
$$

where the superscripts $\mathrm{n}$ and e represent the Local-Level frame (LLF) and Earth-Centered Earth-Fixed (ECEF) frame, respectively. $C$ is the rotation matrix and $\mathrm{A}$ is the direction cosine matrix (also called geometry matrix). $\mathrm{T}$ is the transfer matrix and defined as follows: 
$T^{n}=\left(\left(A^{n}\right)^{T} C_{\phi}^{-1}\left(A^{n}\right)\right)^{-1}\left(A^{n}\right)^{T} C_{\phi}^{-1}$

$C_{\phi}^{-1}$ is a weighted matrix determined by FLL lock detectors in individual PLLs.

The COOP loop can be based on either a least-squares estimation method or on a Kalman filter. In this study, the least-squares method is used. Least-squares estimation is an effective optimal estimation method, especially when measurement redundancy is high. Many fault detection algorithms such as Receiver Autonomous Integrity Monitoring (RAIM) are in fact based on leastsquares estimation, provided redundant measurements are available. Herein, the principle of "using an optimal estimator in GPS positioning to fully utilize measurement redundancy", is put forward from the measurement processing domain into the GPS baseband signal processing domain, which leads to the COOP tracking method. COOP loops allow a GPS receiver to do signal tracking based on the multi-channel vector tracking approach. Furthermore, based on measurement redundancy, blunder detection algorithms and adaptive estimation methods now can be realized at the signal processing stage rather than at the measurement processing stage.

\section{B. Effect of IMU Quality}

In a loosely or tightly coupled GPS/INS for use in urban canyons, the receiver frequently loses phase lock on incoming signals. Therefore the INS in this kind of integrated system must be able to accommodate GPS outages for relatively long periods, e.g., up to $30 \mathrm{~s}$. In an ultra-tightly coupled GPS/INS however, the receiver can track weak GPS signals continuously because of INS aiding. Thus, the INS is constantly corrected by GPS measurements which are typically available every $1 \mathrm{~s}$. Consequently, the maximum INS prediction duration may be limited to $1 \mathrm{~s}$ in many common scenarios. This implies that a low-cost Micro Electro-Mechanical System (MEMS) IMU might be acceptable for ultra-tightly coupled GPS/INS for certain applications.

INS velocity errors caused by sensor errors over one second can be estimated using velocity error signatures as (Scherzinger, 2004)

$$
\begin{aligned}
& \delta V=b_{a} t=b_{a} \\
& \delta V=-\frac{1}{6} g b_{g} t^{2}=-\frac{1}{6} g b_{g}
\end{aligned}
$$

where $\delta V$ is the velocity error, $b_{a}$ is the accelerometer (2) bias and $b_{g}$ is the gyro bias, $g$ is the gravity, and $t$ is the time interval.

With COOP loops, the effects of an INS positioning error on the receiver Doppler prediction and clock error compensation will be limited. Therefore, the accuracy for aiding velocity need not be accurate to $1 \mathrm{~cm} / \mathrm{s}$ level any more, as pointed out by Soloviev et al. (2004a). In this research, a velocity error of $0.1 \mathrm{~m} / \mathrm{s}$ is used for the Doppler aiding accuracy, which makes it feasible to use a lower grade IMU quality with either an accelerometer bias of $10 \mathrm{mg}$ or a gyro bias of $3.4^{\circ} \mathrm{s}$.

In actual applications, a velocity error of $0.1 \mathrm{~m} / \mathrm{s}$ in $1 \mathrm{~s}$ can be achieved with many MEMS IMUs available today, such as the Crista IMU from Cloud Cap Technology, as described by Godha and Cannon (2005). The in-run gyro biases and accelerometer biases of this unit are about $0.3 \%$ and $2.5 \mathrm{mg}$, respectively.

\section{Effect of Allan Oscillator Phase Noise on Carrier Phase Tracking}

The measurement characteristics of a low-cost Temperature-Compensated Crystal Oscillator (TCXO) are similar to those of a low-cost gyro. Oscillator clock errors can be divided into turn-on bias, in-run drift and the remaining colored noise components, the latter being characterized by the Allan Variance. In most GPS/INS systems, the clock bias and drift are estimated and then compensated using a Kalman filter.

In theory, since the clock noise described by the Allan variance is characteristically colored, it can be modeled and thus partly estimated by GPS/INS Kalman filters. If the colored noise is modeled perfectly, the remaining part will be limited to white noise, which can be regarded as thermal noise and easily handled by receiver tracking loops. To simplify the filter design, Allan clock noise is regularly assumed to be white noise (Brown and Hwang, 1992) and thus will not be estimated. Most of the energy of the colored noise is located in the low frequency band in the frequency domain. For this reason, when low-pass loop filters in a receiver try to eliminate the thermal noise from the signal, most of the clock noise passes through these low-pass filters, since it is mixed with the GPS signal in the low frequency band of the spectrum. Therefore, Allan oscillator phase noise must be considered in receiver design, especially in weak signab) environments. The effect of the correlated clock noise on signal tracking is discussed in Kaplan (1996). 


\section{Determination of Coherent Integration Time for Internal Individual DLLs/PLLs}

The tracked GPS signal power after accumulators can be expressed as (Raquet, 2004)

$$
\begin{aligned}
& I=\frac{A M_{E}}{\sqrt{2}} \frac{\sin (\pi \Delta f T)}{\pi \Delta f T} R(\tau) D \cos \left(\pi \Delta f T+\phi_{0}\right) \\
& Q=\frac{A M_{E}}{\sqrt{2}} \frac{\sin (\pi \Delta f T)}{\pi \Delta f T} R(\tau) D \sin \left(\pi \Delta f T+\phi_{0}\right)
\end{aligned}
$$

where $M_{E}$ is the number of samples accumulated in one sample period, $\Delta f$ is the frequency error over the integration interval, $R$ is the self-correlation function of PRN code, and $\mathrm{D}$ is the navigation data bit modulated on the signal. In Equation (4), the tracked signal undergoes a power loss due to the aiding velocity errors, with the loss characterized by the function $\frac{\sin (\pi \Delta f T)}{\pi \Delta f T}$. Since the L1 carrier wavelength is about $19 \mathrm{~cm}$, a velocity error of 0.1 $\mathrm{m} / \mathrm{s}$ will lead to a maximum Doppler error of $0.5 \mathrm{~Hz}$ along a given LOS vector. The resulting signal power loss over the total integration time due to this phenomenon is shown in Figure 5. A coherent integration time of $1 \mathrm{~s}$ would result in a power loss of $4 \mathrm{~dB}$.

The design of receiver tracking loops using continuous update approximation is discussed in details in Kaplan (1996). Stephens and Thomas (1995) have shown that, when the product of loop bandwidth $\left(B_{n}\right)$ and coherent integration time $\left(T_{c o h}\right)$ is much greater than 0.1 or close to 1 , the continuous update approximation does not hold. Gao (2007) and Ilir et al. (2007) give the expressions for the signal tracking errors of both FLL and PLL in a digital GPS receiver. Since the Doppler uncertainty from INS aiding is $0.5 \mathrm{~Hz}$, as shown in Figure 5, coherent integration time should be shorter than $0.2 \mathrm{~s}$ to satisfy the condition $B_{n} \times T_{c o h}<0.1$ or $B_{n} \times T_{c o h}<<1$.

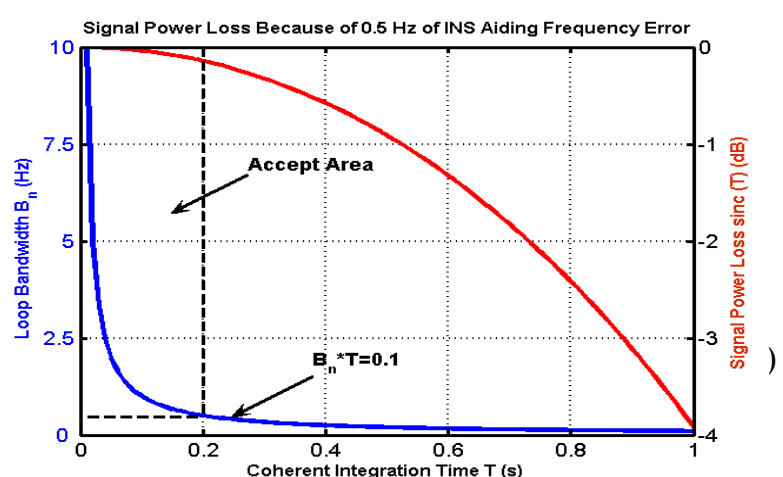

Fig. 5 Signal Power Loss over Integration Time

Another factor that limits the choice of very long coherent integration time is the navigation data bit transition. Soloviev et al. (2004a) presents an energybased bit estimation algorithm to account for possible bit transitions during signal integration. The algorithm searches for the bit combination every $20 \mathrm{~ms}$ to maximize signal energy over the tracking integration interval. This approach presumes that the right bit combination is the one that maximizes the signal energy over the tracking integration interval, namely, the Signalto-Noise Ratio (SNR) after $20 \mathrm{~ms}$ of integration should be above zero. This yields a limitation of $-157 \mathrm{dBm}$ for this approach (Gao, 2007), as given by:

$$
\begin{aligned}
C & =N_{0} B S N R_{I 20} \\
& =-204+10 \log \left(\frac{1000}{20}\right)+0 \\
& =-157 \mathrm{dBm}
\end{aligned}
$$

where $S N R_{I 20}$ is the signal-to-noise ratio after $20 \mathrm{~ms}$ coherent integration, $N_{0}$ is the environmental thermal noise and $N_{0}=-204 \mathrm{dBm} . \mathrm{B}$ is the bandwidth of the phase tracking loop using $20 \mathrm{~ms}$ coherent integration time and $B=10 \log \left(\frac{1000}{20}\right) \mathrm{Hz}$.

Equation (5) illustrates that an incoming signal lower than $-157 \mathrm{dBm}$, which equals to $17 \mathrm{~dB}-\mathrm{Hz}$, will fail the assumption implied in this algorithm and, hence, the energy-based bit detection approach. In this case, increasing the length of coherent integration time cannot help to track this very-weak signal. 
In consideration of the above factors, a maximum coherent integration time of $100 \mathrm{~ms}$ is used in this paper.

\section{TEST SETUP AND TEST RESULTS}

Several static and dynamic tests were conducted to assess the performance of the above INS-assisted HSGPS receiver. In the static case, a scenario where a GPS receiver is tracking strong and weak signals at the same time is simulated to examine the performance of COOP loops. In the dynamic case, a scenario where a GPS receiver is tracking all weak signals at the same time is simulated to assess the tracking sensitivity of the ultratightly coupled GPS/INS system.

\section{A. Simulation Test Tools}

For simulating the incoming GPS signal and IMU measurements, the GPS simulator GPS_GenTM, developed previously by Dong et al (2004), and an INS simulator INS_Sim developed by Gao (2007) were used. Figure 6 shows the architecture of the INS simulator.

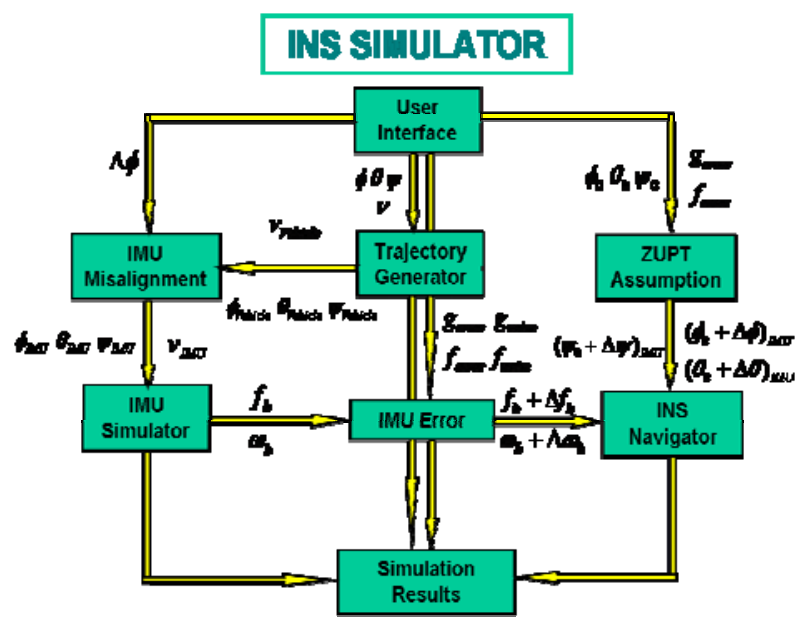

Fig. 6 The Architecture of INS Simulator

\section{B. Static Test Scenario}

The test summary is shown in Figure 7. The total duration of the data collection was $50 \mathrm{~s}$. During the first $14 \mathrm{~s}$, the system initialization, including GPS signal acquisition and ephemeris collection, was performed. Then, from 14 to $50 \mathrm{~s}$, the INS output, i.e., the user velocity and position from the INS, was fed to the GPS receiver to assist with the GPS signal tracking. To simplify the test analysis, INS operated in stand-alone mode for this $36 \mathrm{~s}$ aiding period, such that it kept accumulating errors. The GPS simulator scenario was designed to output strong GPS signals ( $45 \mathrm{~dB}-\mathrm{Hz})$ for all satellites, except for PRN 07, as illustrated in Figure 7. For PRN 07, the signal power was $45 \mathrm{~dB}-\mathrm{Hz}$ during the first $20 \mathrm{~s}$ period and then reduced gradually to $15 \mathrm{~dB}-\mathrm{Hz}$ by the GPS simulator over the next $20 \mathrm{~s}$ period. During the last $10 \mathrm{~s}$ period, the signal power of PRN 07 was kept at $15 \mathrm{~dB}-\mathrm{Hz}$.

The error characteristics of the IMU data simulated were similar to a tactical grade HG1700 IMU, as discussed by Petovello (2003). Figure 8 shows the interface of INS Sim and

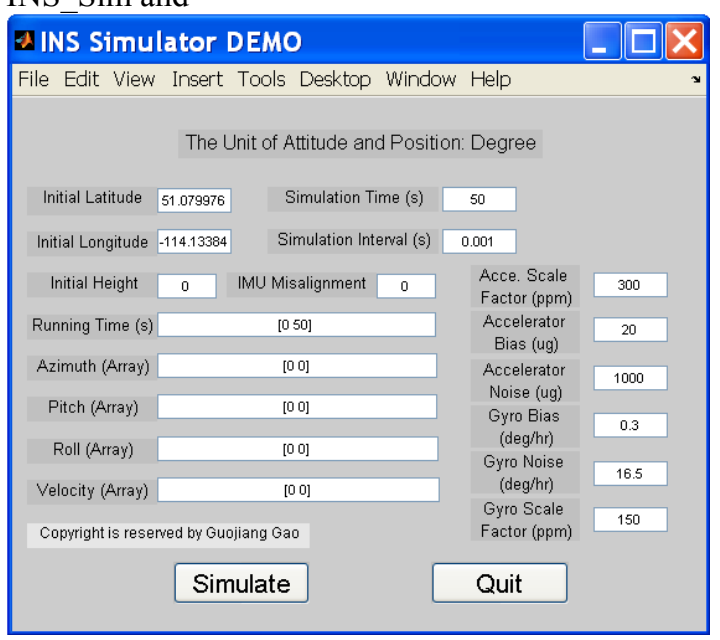

Fig. 8 The Interface of INS Simulator

Table 3 lists the parameters used for simulating the IMU data. The simulation assumes that the INS has been initialized with GPS measurements. So the accelerometer bias residual and gyro bias residual were limited to around $20 \mu \mathrm{g}$ and $0.3 \% \mathrm{hr}$ respectively. The IMU noise bandwidth was kept at about $10 \mathrm{~Hz}$ so that the gyro noise was equal to $16.5^{\circ} / \mathrm{hr}$. The pitch and roll alignment errors were $0.01^{\circ}$ and the heading alignment error was $0.05^{\circ}$.
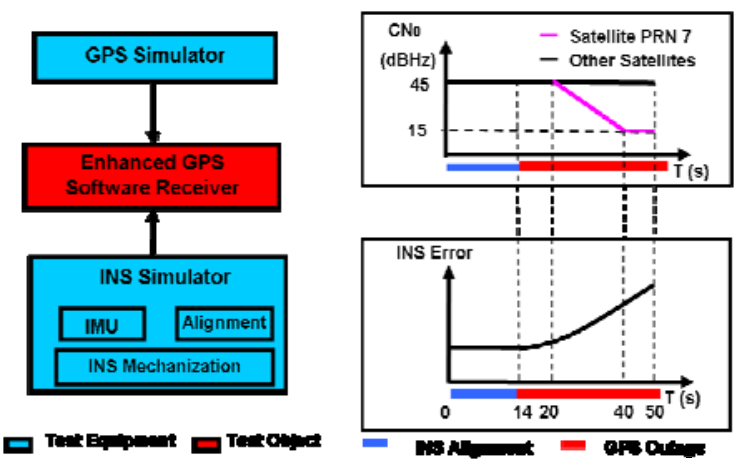
Fig. 7 Static Test Setup for INS-assisted HSGPS Receiver

\begin{tabular}{|c|c|c|c|c|}
\hline \multicolumn{4}{|c|}{ A INS Simulator DEMO } & \multirow{2}{*}{$-\square$} \\
\hline File Edit View & Insert & Tools Desktop Windo & Help & \\
\hline \multicolumn{5}{|c|}{ The Unit of Attitude and Position: Degree } \\
\hline Initial Latitude & 51.079976 & Simulation Time (s) & 50 & \\
\hline Initial Longitude & -114.13384 & Simulation Interval (s) & 0.001 & \\
\hline Initial Height & 0 & IMU Misalignment & $\begin{array}{l}\text { Acce. Scale } \\
\text { Factor (ppm) }\end{array}$ & 300 \\
\hline Running Time (s) & & {$[050]$} & $\begin{array}{c}\text { Accelerator } \\
\text { Bias (ug) }\end{array}$ & 20 \\
\hline Azimuth (Array) & & {$[00]$} & Accelerator & 1000 \\
\hline Pitch (Array) & & {$[00]$} & $\begin{array}{l}\text { Noise (ug) } \\
\text { Gyro Bias }\end{array}$ & \\
\hline Roll (Array) & & {$[00]$} & (deg/hr) & 0.3 \\
\hline Velocity (Array) & & {$[00]$} & $\begin{array}{l}\text { Gyro Noise } \\
\text { (deg/hr) }\end{array}$ & 16.5 \\
\hline Copyright is resen & red by Guo & jiang Gao & $\begin{array}{l}\text { Gyro Scale } \\
\text { Factor (ppm) }\end{array}$ & 150 \\
\hline & Sim & nulate & Quit & \\
\hline
\end{tabular}

Fig. 8 The Interface of INS Simulator

Table 3 Simulated-INS Parameters

\begin{tabular}{c|c|c} 
& Accelerometer & Gyro \\
\hline Scale Factor & $300 \mathrm{ppm}$ & $150 \mathrm{ppm}$ \\
\hline $\begin{array}{c}\text { Bias } \\
\text { Residual }\end{array}$ & $20 \mu \mathrm{g}$ & $0.3 \% \mathrm{hr}$ \\
\hline $\begin{array}{c}\text { Random } \\
\text { Noise }\end{array}$ & $1000 \mu \mathrm{g}$ & $5.5^{\circ} / \sqrt{\mathrm{hr} \cdot \mathrm{Hz}}$ \\
\hline
\end{tabular}

In this test, the ephemeris at 19:27 on July 06, 2000 in UTC time was chosen for the GPS signal simulation. At that time, seven satellites were visible from the test position (Latitude $51^{\circ}$ North, longitude $-114^{\circ}$ West), such that the GDOP and HDOP were both less than 2 during the test period. The PRNs visible above a $15^{\circ}$ masking angle were 04, 05, 07, 09, 17, 24 and 30. The receiver parameters used in this static test were $3 \mathrm{~Hz}$ bandwidth and $20 \mathrm{~ms}$ coherent integration time for COOP, and 0.2 $\mathrm{Hz}$ bandwidth and $100 \mathrm{~ms}$ coherent integration time for individual PLL. To assess the improvement provided by INS aiding, the standard version of the software GPS receiver without INS aiding was also used in all tests to measure normal GPS tracking performance. In this standard GPS receiver, $10 \mathrm{~Hz}$ bandwidth and $10 \mathrm{~ms}$ coherent integration time were used for signal tracking. In the test, previous experience was used to empirically select these parameters for this comparison. The simulated INS velocity error is shown in Figure 9. It is noted that, at the 50-s point, INS velocity errors reach $0.1 \mathrm{~m} / \mathrm{s}$, which is similar to the velocity accuracy available from a MEMS IMU, during $1 \mathrm{~s}$ in the integrated GPS/INS system. As shown in Figure 9, the
INS errors have low frequency content. In contrast to GPS errors, their time growth is somewhat smooth.

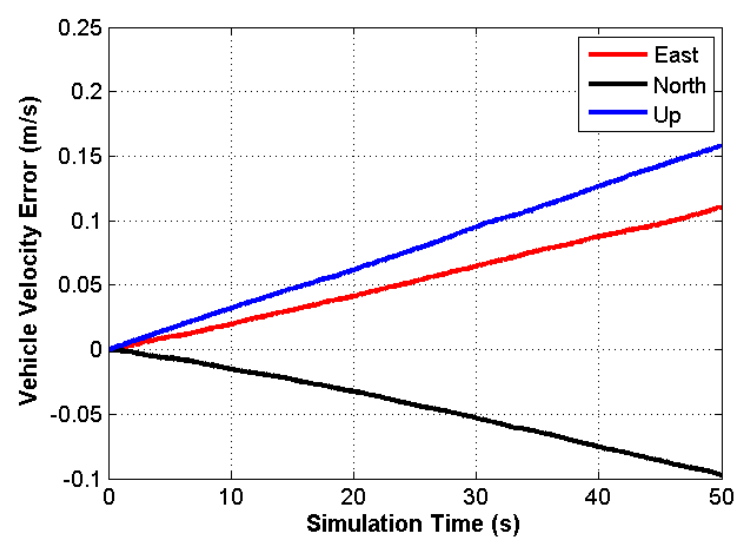

Fig. 9 Simulated INS Velocity Error

\section{Static Test Results}

Figure 10 shows the carrier-to-noise (C/No) density of satellite PRN 07 over the entire test period both with and without INS aiding. Figure 11 shows the carrier phase tracking error of individual PLLs and Figure 12 shows the total carrier phase tracking errors with and without INS aiding. In Figure 12, for computing the errors, the "true" reference carrier phase was determined by another test where satellite PRN 07 was kept at $45 \mathrm{~dB}-\mathrm{Hz}$ and all other scenario parameters kept the same as the present test. The figures show that, although the signal power of satellite PRN 07 is attenuated from 45 to $15 \mathrm{~dB}-\mathrm{Hz}$ during the last 30-s period, the INS-assisted GPS receiver can track the satellite with carrier phase locked. However, a standard GPS receiver without INS aiding cannot track satellite PRN 07 any longer when the signal power is lower than $30 \mathrm{~dB}-\mathrm{Hz}$.

As stated previously, the first 14-s period of the test is used to finish frame synchronization and receive codetime-delay $(\tau)$ from the navigation data; when the latter is received, the receiver continues to output positioning solutions from the $14 \mathrm{~s}$ point onward. Since INS is mainly used to aid carrier phase tracking loops in this paper, only the velocity solution is shown in Figure 13. For the standard receiver without INS aiding, because of the large tracking errors on satellite PRN 07 around epoch $30 \mathrm{~s}$, there are two large faults at epoch $31 \mathrm{~s}$ and $32 \mathrm{~s}$, which are about $4 \mathrm{~m} / \mathrm{s}$ and $11.5 \mathrm{~m} / \mathrm{s}$, respectively. The reason for these two faults in the GPS solution is that an epoch-by-epoch least-squares positioning approach is used here to calculate receiver velocity. In this basic least-squares estimator, no fault testing is performed. 
After the 32-s epoch, the standard receiver loses lock on satellite PRN 07 so that velocity error returns to a normal level.

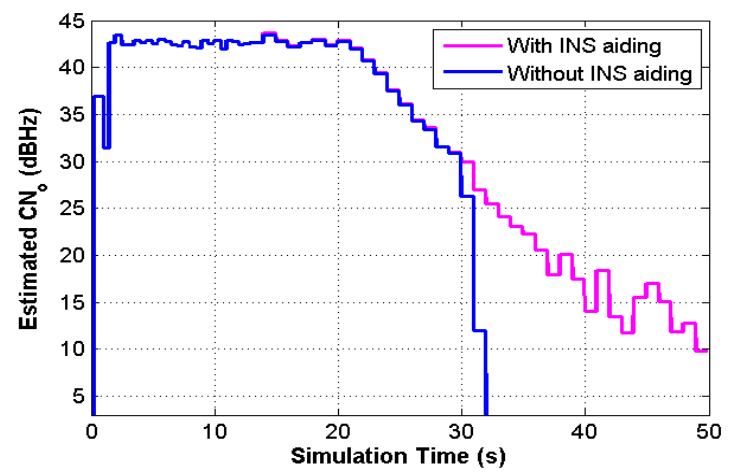

Fig. $10 \mathrm{CN}_{0}$ of PRN 07 Tracked in Static Test

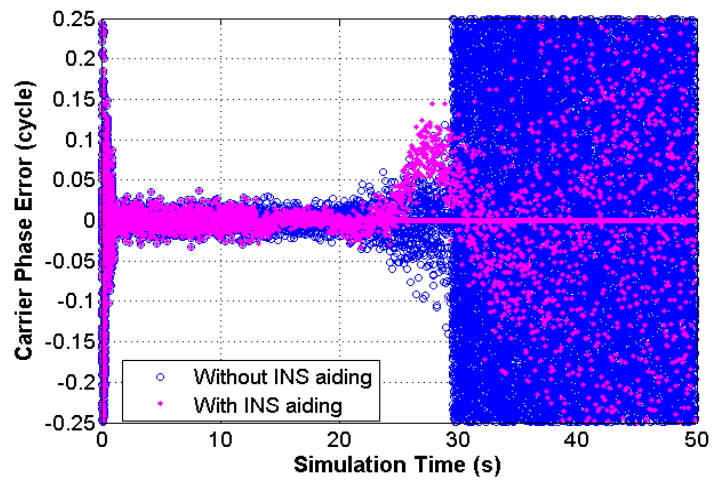

Fig. 11 PLL Carrier Phase Error in Static Test

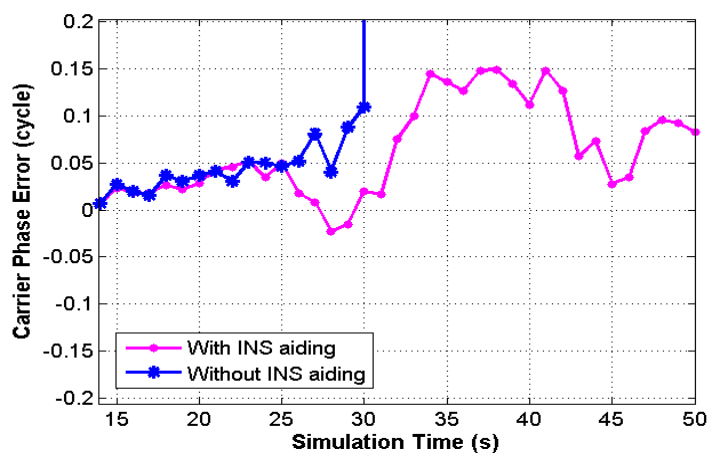

Fig. 12 Total Carrier Phase Error in Static Test

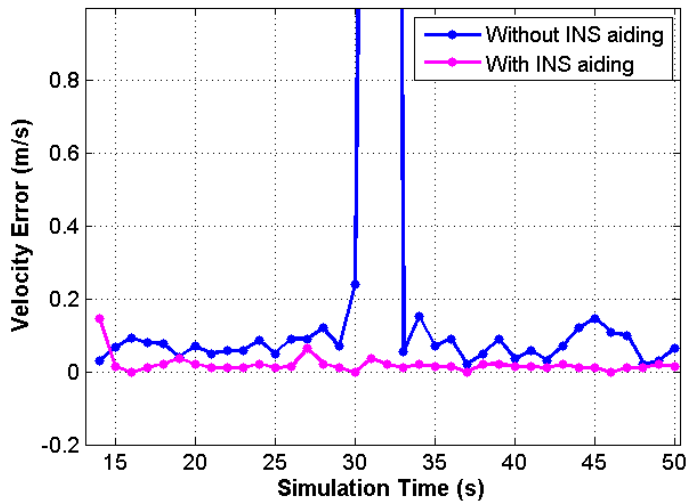

Fig. 13 Horizontal Velocity Error in Static Test

Figure 12 and Figure 13 show that the signal tracking sensitivity of the INS-assisted GPS receiver is improved for at least $15 \mathrm{~dB}$ as compared to that of the standard GPS receiver when there are multiple strong signals available. This improvement can be attributed to two aspects:

1. Since INS aiding removes the signal Doppler and thus decreases the receiver dynamics uncertainty, a long coherent integration (here is $100 \mathrm{~ms}$ ) is used for weak signal tracking.

2. Since the COOP tracking method is used, the strong signals aid the weak signal tracking. In this test, the tracking of other strong satellites is of benefit to the tracking of satellite PRN 07, as will be explained later in this section.

Figure 14 shows the carrier phase tracking error of satellite PRN 07 for the INS-assisted GPS receiver, with and without the use of COOP estimators. In the case when COOP is not used, the individual PLL parameters are kept the same as for the case with COOP estimators, i.e. $0.2 \mathrm{~Hz}$ bandwidth and $100 \mathrm{~ms}$ coherent integration time. From Figure 14, it can be seen that, although the coherent integration time is $100 \mathrm{~ms}$, without the COOP loop, the tracking performance is even worse than that of a standard GPS receiver (without INS aiding) where coherent integration time is $10 \mathrm{~ms}$. At epoch $26 \mathrm{~s}$, the PLL loses lock and the carrier phase error drifts away rapidly. The reason for the loss of phase lock and poor performance of the INS-aided receiver without COOP in Figure 14 is shown in Figure 15, which gives the carrier Doppler of satellite PRN 07 tracked by COOP and individual PLLs separately. Because of strong signals in view, COOP can perfectly track Doppler residuals caused by the INS aiding errors (shown in Figure 9). Since COOP tracking compensates for the INS aiding errors, combined COOP and INS aiding provides a nearly 
perfect reference for receiver dynamics. Therefore, even though the power of PRN 07 drops to $15 \mathrm{~dB}-\mathrm{Hz}$ during the last $30 \mathrm{~s}$, the carrier Doppler tracked by individual PLLs is close to zero. If COOP were not used, the individual PLL would have to track the INS aiding Doppler error, as shown in Figure 14. When the coherent integration time is very long, the INS aiding Doppler error will fail the pure PLL tracking.

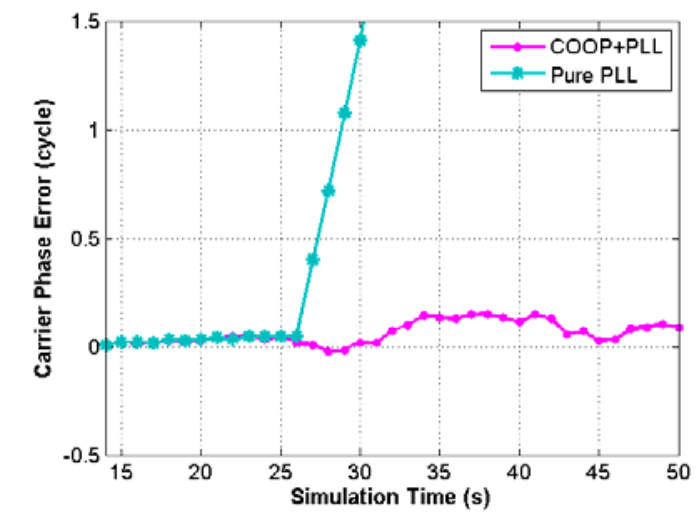

Fig. 14 Total Carrier Phase Error of PLL-Only Receiver with INS Aiding in Static Test

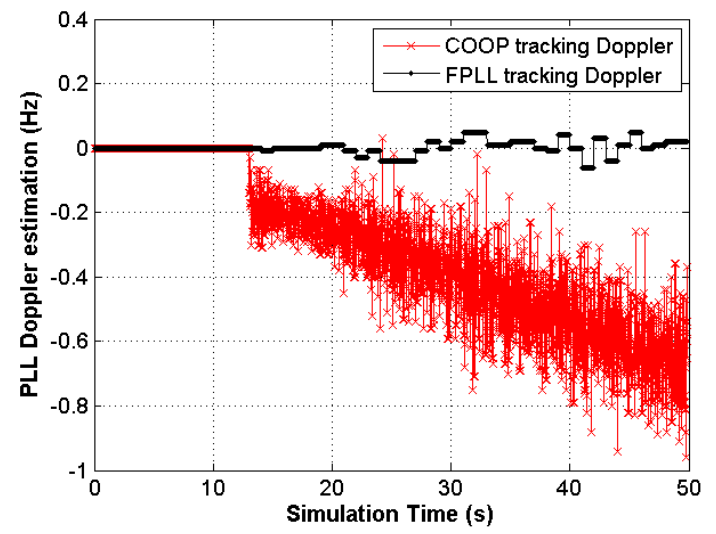

Fig. 15 Carrier Doppler Tracked by PLL and CO-OP Separately in Static Test

To investigate the signal tracking stability of the INSassisted HSGPS receiver while the receiver parameters vary, different combinations of receiver tracking parameters were examined when all incoming GPS signals were kept at $15 \mathrm{~dB}-\mathrm{Hz}$. In this static test, the parameters adopted for the three test receivers are listed in Table 4: Receiver one used very narrow noise bandwidths for both COOP and FPLL, with a very long FPLL integration time, namely, $2 \mathrm{~s}$. In receiver two, wider noise bandwidth and shorter integration time were adopted. However, compared to those used in a standard receiver, these parameters were still very stringent. Receiver three used a set of parameters that can also be used in a standard GPS-only receiver in static situations.

The test results statistics are summarized in Table 5, including the receiver PLL discriminator output and the carrier Doppler tracked by the COOP, respectively. The standard derivations of these two observations are used to assess carrier phase tracking performance of the three receivers. When the receiver parameters become more stringent from receiver three to receiver one, the standard deviation of the carrier Doppler tracked by COOP decreases, which means that COOP can track the incoming signals with increasing accuracy. One can also see that the $15 \mathrm{~dB}-\mathrm{Hz}$ signal is locked in the entire test and all three receivers can output reasonable velocity solutions. Based on the test results, it is evident that, while the adopted receiver parameters vary in a large range, the INS-assisted HSGPS receiver presents very stable performance in both phase and code tracking, although there are cycle slips present in all three receivers. Finally, it should be noted that due to different receiver dynamics, different levels of signal power, etc, the range of suitable parameters for the INS-assisted HSGPS receiver may change from one case to another. In dynamic situations, a narrower range of suitable receiver parameters is expected.

Table 4 Parameters Adopted in Three Receivers

\begin{tabular}{c|c|c|c}
\hline $\begin{array}{c}\text { Adopted } \\
\text { Receiver } \\
\text { Parameters }\end{array}$ & $\begin{array}{c}\text { Receiver } \\
\text { One }\end{array}$ & $\begin{array}{c}\text { Receiver } \\
\text { Two }\end{array}$ & $\begin{array}{c}\text { Receiver } \\
\text { Three }\end{array}$ \\
\hline $\begin{array}{c}\text { Phase Noise } \\
\text { Bandwidth of } \\
\text { COOP (Hz) }\end{array}$ & 0.2 & 1.2 & 3 \\
\hline $\begin{array}{c}\text { Phase Noise } \\
\text { Bandwidth of } \\
\text { FPLL (Hz) }\end{array}$ & 0.1 & 0.2 & 0.2 \\
\hline $\begin{array}{c}\text { Coherent } \\
\text { Integration Time } \\
\text { of COOP (ms) }\end{array}$ & 20 & 20 & 20 \\
\hline $\begin{array}{c}\text { Non-Coherent } \\
\text { Integration Times } \\
\text { of COOP }\end{array}$ & 1 & 1 & 1 \\
\hline $\begin{array}{c}\text { Coherent } \\
\text { Integration Time } \\
\text { of FPLL (ms) }\end{array}$ & 100 & 100 & 100 \\
\hline $\begin{array}{c}\text { Non-Coherent } \\
\text { Integration Times } \\
\text { of FPLL }\end{array}$ & 20 & 10 & 10 \\
\hline
\end{tabular}


Table 5 Tracking Result Statistics of Different Receivers When the Incoming Signal is $15 \mathrm{~dB}-\mathrm{Hz}$

\begin{tabular}{c|c|c|c}
\hline Observation Name & $\begin{array}{c}\text { Receiver } \\
\text { One }\end{array}$ & $\begin{array}{c}\text { Receiver } \\
\text { Two }\end{array}$ & $\begin{array}{c}\text { Receiver } \\
\text { Three }\end{array}$ \\
\hline $\begin{array}{c}\text { Estimated Carrier } \\
\text { Phase Error Std on } \\
\text { Satellite PRN 07 } \\
\text { (cycle) }\end{array}$ & 0.029 & 0.030 & 0.030 \\
\hline $\begin{array}{c}\text { COOP Tracking } \\
\text { Doppler Std on } \\
\text { Satellite PRN 07 } \\
\text { (Hz) }\end{array}$ & 0.4 & 1.3 & 1.9 \\
\hline $\begin{array}{c}\text { Estimated C/No } \\
\text { Mean on Satellite } \\
\text { PRN 07 (dB-Hz) }\end{array}$ & 17.9 & 17.8 & 17.8 \\
\hline $\begin{array}{c}\text { Estimated C/No Std } \\
\text { on Satellite PRN 07 } \\
\text { (dB-Hz) }\end{array}$ & 3.1 & 3.2 & 3.1 \\
\hline $\begin{array}{c}\text { Horizontal Velocity } \\
\text { Error Mean (m/s) }\end{array}$ & 0.21 & 0.38 & 0.40 \\
\hline $\begin{array}{c}\text { Horizontal Velocity } \\
\text { Error Std (m/s) }\end{array}$ & 0.16 & 0.23 & 0.30 \\
\hline $\begin{array}{c}\text { Vertical Velocity } \\
\text { Error Mean (m/s) }\end{array}$ & -0.10 & 0.23 & 0.14 \\
\hline $\begin{array}{c}\text { Vertical Velocity } \\
\text { Error Std (m/s) }\end{array}$ & 0.24 & 0.50 & 0.79 \\
\hline
\end{tabular}

\section{Dynamic Test Scenario}

The receiver trajectory and the velocities simulated in the dynamic test are shown in Figure 16 and Figure 17. During the first $20 \mathrm{~s}$, the vehicle moved east with a velocity of $100 \mathrm{~m} / \mathrm{s}$. In the next $30 \mathrm{~s}$, the vehicle made an "S" shaped trajectory, with an angular rate of $6 \%$.

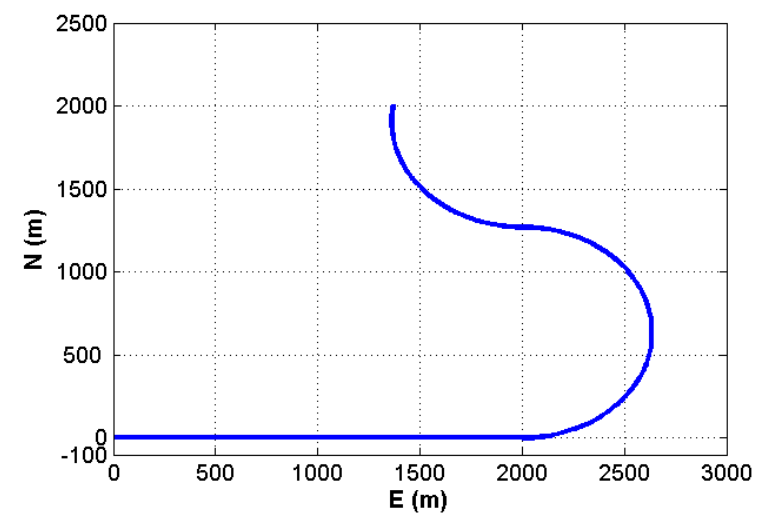

Fig. 16 Vehicle Trajectory in Dynamic Test

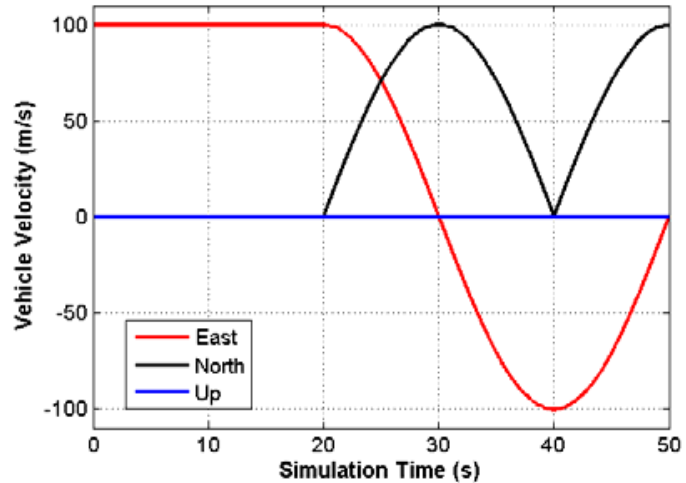

Fig. 17 Vehicle Velocity in Dynamic Test

The change of signal power in the dynamic test is shown in Figure 18. In contrast to the static test, the power of all signals was degraded simultaneously from $45 \mathrm{~dB}-\mathrm{Hz}$ to $25 \mathrm{~dB}-\mathrm{Hz}$ during the period of $20 \mathrm{~s}$ to $30 \mathrm{~s}$. Then the power level for all signals was kept at $25 \mathrm{~dB}-\mathrm{Hz}$ from $30 \mathrm{~s}$ to $40 \mathrm{~s}$, and then increased back to $45 \mathrm{~dB}-\mathrm{Hz}$ during the last $10 \mathrm{~s}$ of the test. The parameters of the INS simulator were the same as those in the static test. The INS velocity errors are shown in Figure 19. GPS parameters used in the standard GPS software receiver were the same as those in the static test, namely $10 \mathrm{~Hz}$ bandwidth and $10 \mathrm{~ms}$ coherent integration time. For INSassisted HSGPS, the bandwidth was $0.4 \mathrm{~Hz}$ for individual PLL and $3 \mathrm{~Hz}$ for COOP. The coherent integration time of $100 \mathrm{~ms}$ for individual PLL and $20 \mathrm{~ms}$ for COOP were used. The other parameters were kept same as those of the static test.

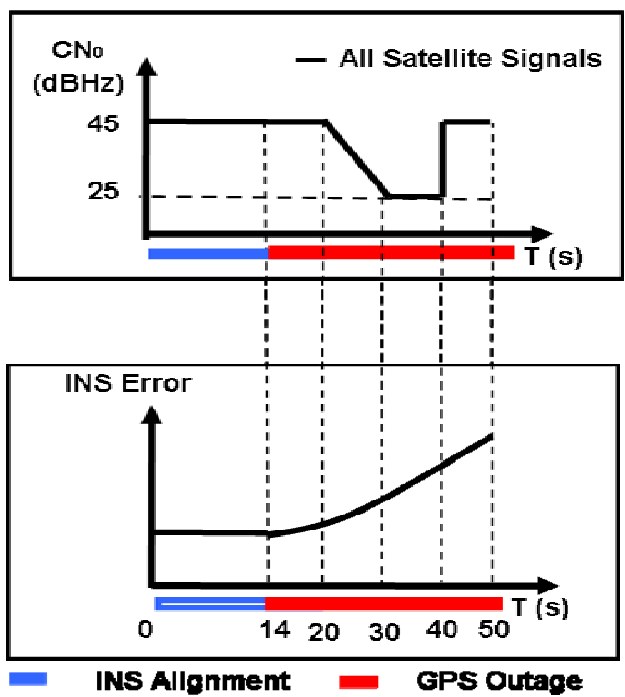

Fig. 18 Simulated Change of Signal Power 


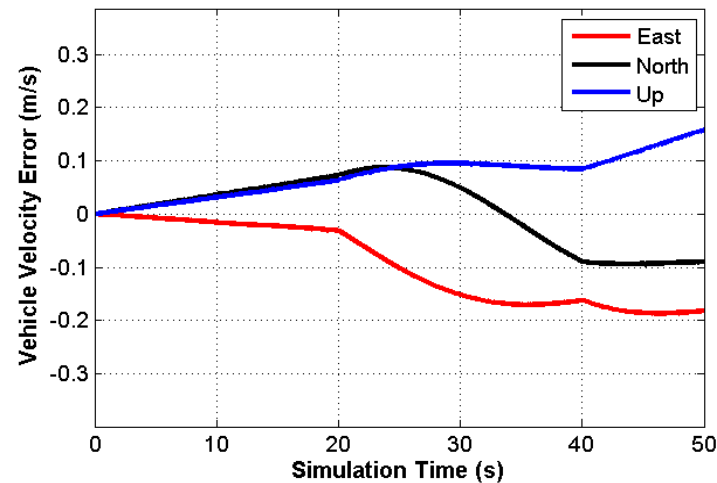

Fig. 19 INS Velocity Error in Dynamic Test

\section{E. Dynamic Test Results}

Figure 20 shows the $\mathrm{C} / \mathrm{No}$ of the received PRN 07 satellite signal during the test period both with and without INS aiding. Figure 21 shows the PLL carrier phase tracking errors, Figure 22 shows the total carrier phase errors, and Figure 23 shows the horizontal velocity errors for the INS-assisted HSGPS receiver and the standard GPS receiver. It can be seen from these figures that the tracking performances of the standard receiver is very poor under dynamic conditions as compared to those of the INS-assisted HSGPS receiver. Figure 21 and Figure 22 show clearly that the standard GPS receiver cannot lock on the incoming carrier phase when the vehicle starts to make the "S" shaped trajectory. During the period between $20 \mathrm{~s}$ and $28 \mathrm{~s}$, although the individual PLLs in the standard receiver show lock on the incoming carrier phase in Figure 21, there are cycle slips due vehicle dynamics. From epoch $28 \mathrm{~s}$ onward, the standard receiver stops to output the GPS solution. In contrast, the INS-assisted HSGPS receiver can track the incoming weak signals down to $25 \mathrm{~dB}-\mathrm{Hz}$ with carrier phase locked during the entire test.

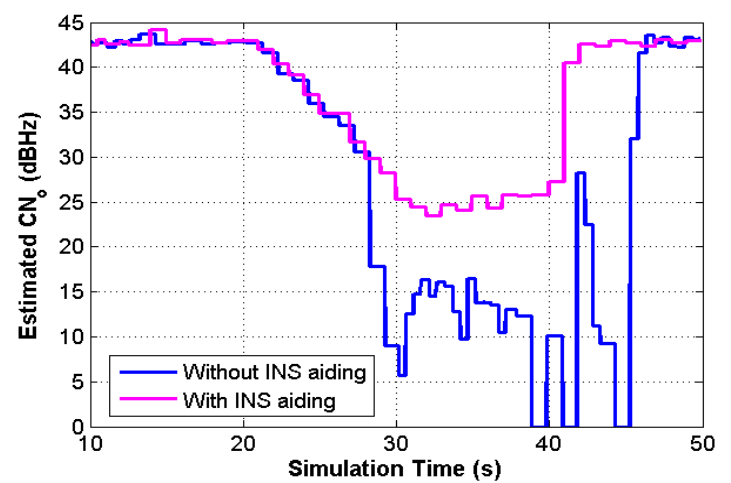

Fig. $20 \mathrm{CN}_{0}$ of PRN 07 in Dynamic Test

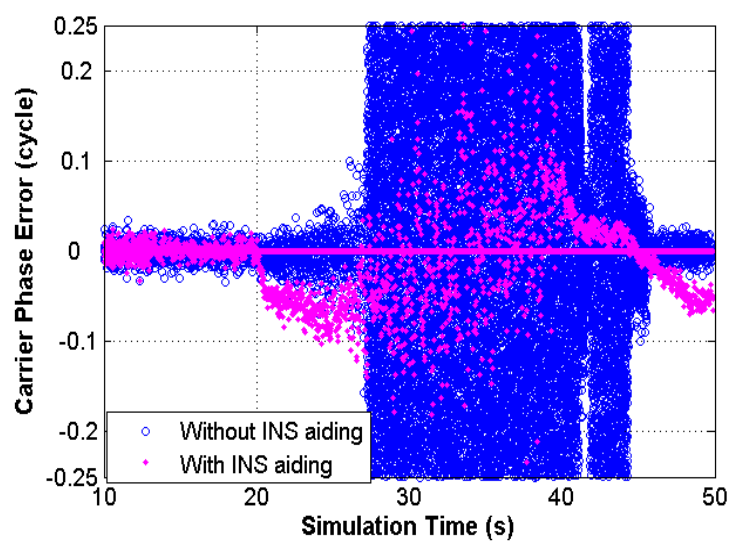

Fig. 21 PLL Carrier Phase Error in Dynamic Test

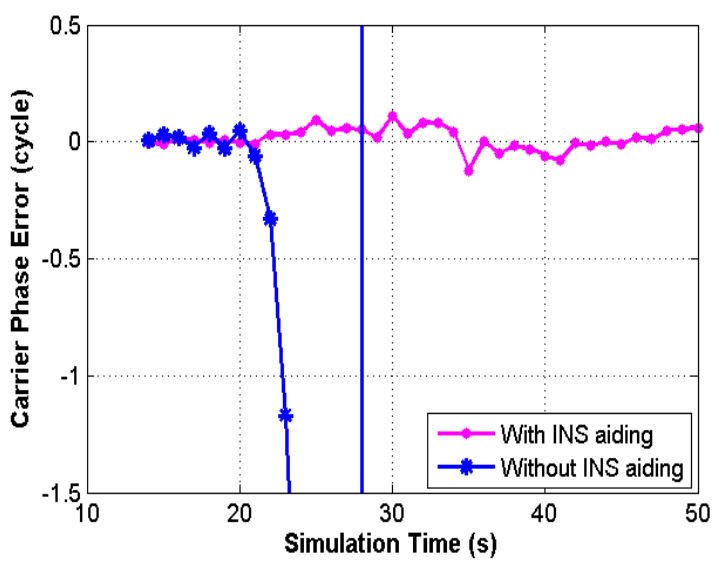

Fig. 22 Total Carrier Phase Error in Dynamic Test

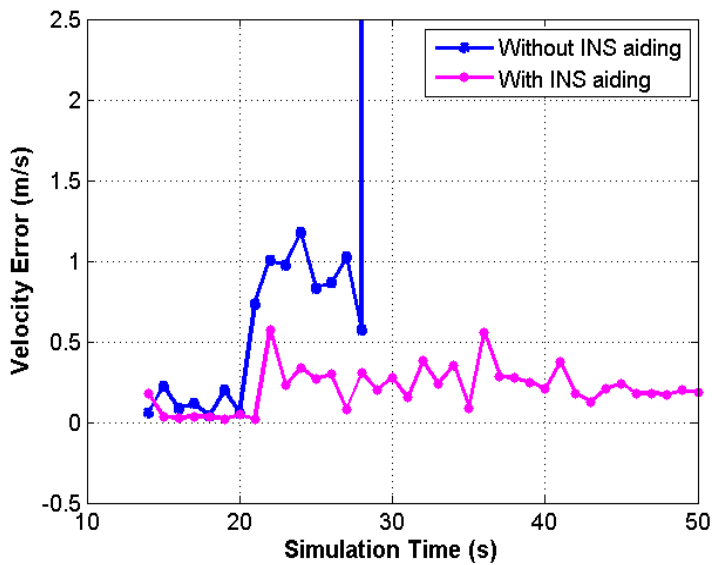

Fig. 23 Horizontal Velocity Error in Dynamic Test 


\section{CONCLUSIONS}

This paper proposes a novel design for an INS-assisted GPS receiver to improve GPS tracking performance for navigation in degraded signal environments. The effects of IMU quality and receiver parameters such as coherent integration time on the designed system are analyzed. Compared to a standard GPS receiver without INS aiding, the INS-assisted GPS receiver proposed here yields much better performance under attenuated signal environments, based on the tests carried out. An analysis of the results leads to the following conclusions:

1. INS aiding can effectively reduce the receiver dynamics uncertainty and improve tracking performance of a standard GPS receiver significantly under both weak signal and high dynamic signal environments.

2. When an INS solution is available, an effective signal tracking strategy can be summarized in three steps. First, the INS solution is implemented in order to remove most of receiver dynamics uncertainty; as a consequence, the residual Doppler signal left for the COOP and FPLLs to track is close to zero. Next, a vector tracking-based COOP loop is designed to track the residual carrier Doppler effectively; since six to 10 satellites are usually in view, COOP

3. tracking yields much better performance than conventional FPLLs, especially under weak signal environments. Finally, FLL-assisted PLLs can be used to track the carrier. Since the Doppler signal is compensated by the combined INS and COOP aiding, the residual Doppler error is close to zero. This significantly decreases carrier phase tracking errors and, therefore, increases the FLL/PLL tracking sensitivity.

4. Although INS error increases rapidly with time during a GPS outage, the INS solution errors change smoothly. These errors can be easily tracked by the COOP method and thus, will not affect signal tracking significantly. Therefore, even if the INS solution error is as large as $0.1 \mathrm{~m} / \mathrm{s}$, an INS-assisted GPS receiver can track a GPS signal that is $30 \mathrm{~dB}$ lower than LOS signals with relatively good positioning accuracy.

5. The combined tracking of the FPLL and COOP loops presented herein have been shown to track signals as low as $15 \mathrm{~dB}-\mathrm{Hz}$. When the signal power is above $22-23 \mathrm{~dB}-\mathrm{Hz}$, this method can lock on the incoming carrier and provide accurate carrier phase measurements. When the signal is lower than $22 \mathrm{~dB}$ $\mathrm{Hz}$ but higher than $15 \mathrm{~dB}-\mathrm{Hz}$, the method can track the incoming carrier most of the time, although cycle slips may occur. When there are several strong signals in view, the receiver can lock the other weak carrier signals as low as $15 \mathrm{~dB}-\mathrm{Hz}$ due to the assistance from the strong signals.

6. Because INS aiding provides most of the Doppler measurements, high receiver dynamics do not affect signal tracking significantly in INS-assisted GPS receivers. With INS aiding and by adopting COOP tracking, long coherent integration can be implemented safely when necessary.

\section{REFERENCES}

Alban S., D. M. Akos and S. M. Rock (2003), Performance Analysis and Architectures for INS-Aided GPS Tracking Loops, in Proceedings of ION National Technical Meeting (NTM), 2224 January, Anaheim CA, pp. 611-622, U.S. Institute of Navigation, Fairfax VA.

Beser J., S. Alexander, R. Crane, S. Rounds and J. Wyman (2002), Trunavtm: A Low-Cost Guidance/Navigation Unit Integrating A SAASM-Based GPS And MEMS IMU In A Deeply coupled Mechanization, in proceedings of ION GPS/GNSS, 24-27 September, Portland OR, pp. 545-555, U.S. Institute of Navigation, Fairfax VA.

Brown, R. G. and P. Y. C. Hwang (1992), Introduction To Random Signals and Applied Kalman Filtering, John Wiley \& Sons, Toronto ON, second edition.

Don K., S. Luis and R. B. Langley (2005), Compensation of the Effects of Phase Wind-up for Improving the Performance of a GPS RTKBased Vehicle Navigation System, in Proceedings of ION GNSS 18th International Technical Meeting of the Satellite Division, 13-16 September, Long Beach, CA, pp. 346-354, Institute of Navigation, Fairfax VA.

Dong L., C. Ma and G. Lachapelle (2004), Implementation and Verification of a SoftwareBased IF GPS Signal Simulator, in proceedings of ION National Technical Meeting (NTM), 26-28 January, San Diego CA, pp. 378-389, Institute of Navigation, Fairfax VA. 
Gao G. (2007), INS-Assisted High Sensitivity GPS Receivers for Degraded Signal Navigation, $\mathrm{PhD}$ Thesis, Published as Reports Number 20252, Department of Geomatics Engineering, University of Calgary, Canada (Available at http:|plan.geomatics.ucalgary.ca).

Gao G. and G. Lacahpelle (2006), INS-Assisted High Sensitivity GPS Receivers for Degraded Signal Navigation, in proceedings of ION GNSS 2006, Fort Worth TX, 26-29 September 2006.

Gautier J. D. and B. W. Parkinson (2003), Using the GPS/INS Generalized evaluation Tool (GIGET) for the Comparison of Loosely Coupled, Tightly Coupled and Ultra-Tightly Coupled Integrated Navigation Systems, in proceedings of ION 59th Annual Meeting/CIGTF 22nd Guidance Test Symposium, 23-25 June, Albuquerque, NM, pp. 65-76, Institute of Navigation, Fairfax VA.

Godha S. and M. E. Cannon (2005), Integration of DGPS with a Low Cost MEMS - Based Inertial Measurement Unit (IMU) for Land Vehicle Navigation Application, in proceedings of ION GPS/GNSS, September13-16, Long Beach CA, pp. 333-345, Institute of Navigation, Fairfax VA.

Gustafson D., J. Dowdle and K. Flueckiger (2000), A High Anti-Jam GPS based Navigator, in proceedings of ION National Technical Meeting (NTM), 26-28 January, Anaheim CA, pp. 495503, Institute of Navigation, Fairfax VA.

Ilir F. P., W. K. Clifford, G. Gao, R. M. William, J. Wang and J. Lavrakas (2007), Discrete vs. Continuous Carrier Tracking Loop Theory, Implementation, and Testing with Large BnT, in proceedings of ION GNSS 2007, 25-28 September, Fort Worth TX, Institute of Navigation, Fairfax VA.

Kaplan E. D., ed (1996), Understanding GPS: Principles and Application, Artech House, Boston MA.

Kreye C., B. Eissfeller and J. Ó. Winkel (2000), Improvements of GNSS Receiver Performance Using Ultra-tightly coupled INS Measurements, in proceedings of ION GPS/GNSS, 19-22 September, Salt Lake City UT, pp. 844-854, Institute of Navigation, Fairfax VA.
Lachapelle, G. (2007), Pedestrian Navigation With High Sensitivity GPS Receivers and MEMS, Journal of Personal and Ubiquitous Computing, Springer, 11, 6, 481-488.

Lachapelle G., H. Kuusniemi and D. T. H. Dao (2003), HSGPS Signal Analysis and Performance under Various Indoor Conditions, in proceedings of ION GPS/GNSS, 9-12 September, Portland OR, pp. 1171-1184, Institute of Navigation, Fairfax VA.

Ma C., R. Klukas and G. Lachapelle (2007), A NonLine-of-Sight Error Mitigation Method for TOA Measurements. IEEE Transactions on Vehicular Technology, 56, 2 (March), 641-651.

Ma C., G. Lachapelle and M. E. Cannon (2004), Implementation of a Software GPS Receiver, in proceedings of ION GPS/GNSS, September 2124, Long Beach CA, pp. 956-970, Institute of Navigation, Fairfax VA.

MacGougan G. D. (2003), High Sensitivity GPS Performance Analysis in Degraded Signal Environments, Master thesis, UCGE Reports Number 20176, Department of Geomatics Engineering, University of Calgary, Canada (Available at http://plan.geomatics.ucalgary.ca).

Petovello M. G. (2003), Real-Time Integration of a Tactical-Grade IMU and GPS for HighAccuracy Positioning and Navigation, $\mathrm{PhD}$ thesis, UCGE Reports Number 20173, Department of Geomatics Engineering, University of Calgary, Canada (Available at http://plan.geomatics.ucalgary.ca).

Raquet J. F. (2004), GPS Receiver Design, ENGO 699.10 Course Notes, Department of Geomatics Engineering, University of Calgary, Canada.

Scherzinger B. (2004), Estimation with Applications to Navigation, ENGO 699.11 Course Notes, Department of Geomatics Engineering, University of Calgary, Canada.

Sennott J. (1997), Robustness of Tightly Coupled Integrations for Real-Time Centimeter GPS Positioning, in proceedings of ION GPS, 16-19 September, Kansas City KS, pp. 655-663, Institute of Navigation, Fairfax VA. 
Soloviev A., F. van Graas and S. Gunawardena (2004a), Implementation of Deeply Integrated GPS/LowCost IMU for Acquisition and Tracking of Low CNR GPS Signals, in proceedings of ION National Technical Meeting (NTM), 26-28 January, San Diego CA, pp. 923-935, Institute of Navigation, Fairfax VA.

Soloviev A., S. Gunawardena and F. van Graas (2004b), Deeply Integrated GPS/Low-Cost IMU for Low CNR Signal Processing: Flight Test Results and Real Time Implementation, in proceedings of ION GNSS 17th International Technical Meeting of the Satellite Division, 21-24 September, Long Beach CA, pp. 1598-1608, Institute of Navigation, Fairfax VA.

Stephens S. A. and J. B. Thomas(1995), Controlled-Root Formulation for Digital Phase-Locked Loops, IEEE Transactions on Aerospace and Electronic Systems, Vol. 31, No. 1, pp. 78-95.
Tetewsky, A. K. and F. E. Mullen (1996), Carrier phase wrap-up induced by rotating GPS antennas, in Proceedings of the Institute of Navigation ION AM-96, Cambridge, MA, pp. 21-28, , Institute of Navigation, Fairfax VA.

Van Diggelen F. and C. Abraham (2001), Indoor GPS Technology, CTIA Wireless-Agenda, Dallas, May.

Watson, R., G. Lachapelle, R. Klukas, S. Turunen, S. Pietilä and I. Halivaara (2006), Investigating GPS Signals Indoors with Extreme High-Sensitivity Detection Techniques, Navigation, Institute of Navigation, 52, 4, 199-213.

Zhodzishsky M., S. Yudanov, V. Veitsel and J. Ashjaee (1998), COOP Tracking for Carrier Phase, in proceedings of ION GPS, 15-18 september, Nashville, Tennessee, pp. 653-664, Institute of Navigation, Fairfax VA. 